\title{
Bulantı ve Kusma ile Kendini Gösteren İki Rabdomiyoliz Vakası
}

\author{
Zeki Kemeç", Selçuk Akın, Mehmet Mahfuz Șıkgenç
}

D0I: $10.17944 / m k u t f d .701359$

Zeki Kemeç: Uzm. Dr., Batman Bölge Devlet Hastanesi, Nefroloji Kliniği, Batman Email: zekikemec@gmail.com

ORCID iD: https://orcid.org/0000-0003-4943-6502

Selçuk Akın: Uzm. Dr., Batman Bölge Devlet Hastanesi, Biyokimya Kliniği, Batman Email: selcuk_hekim@hotmail.com ORCID iD: https://orcid.org/0000-0001-9154-6030

Mehmet Mahfuz Șıkgenç: Uzm. Dr., Batman Bölge Devlet Hastanesi, iç Hastalıkları Kliniği, Batman Email: mehmetmahfuz@hotmail.com

ORCID iD: https://orcid.org/0000-0003-1086-6580

Bildirimler/Acknowledgement

* Sorumlu Yazar/Corresponding Author

Cıkar Çatıșması/Conflict of Interest

Yazarlar bu makale ile ilgili herhangi bir çıkar catısması bildirmemișlerdir.

The authors declare that they have no conflict of interests regarding content of this article.

Maddi Destek/Financial Support

Yazarlar bu makale ile ilgili herhangi bir finansal destek bildirmemișlerdir.

The Authors report no financial support regarding content of this article.

\section{Etik Beyan/Ethical Declaration}

Yazarlar, bu çalıșmada tanımlanan olgudan gerekli izin alınarak "Aydınlatılmıs onam formu"nun düzenlenmis olduğunu, çalıșmanın yürütülmesi esnasında Helsinki Beyannamesi 2013, ICJM tavsiyeleri ile COPE'un Editör ve Yazarlar için Uluslararası Standartlarının yanısıra ilgili diğer biyoetik kılavuzların dikkate alındığını beyan etmișlerdir.

Informed consent was obtained from the participant and Helsinki Declaration rules were followed to conduct this study.

Gelis/Received: 14.05 .2020 Kabul/Accepted: 06.09.2020

e-ISSN: 2149-3103

Web: http://dergipark.gov.tr/mkutfd
Öz

Bulantı ve Kusma ile Kendini Gösteren iki Rabdomiyoliz Vakası

Çok farklı nedenlerden kaynaklanabilen rabdomiyolizin travmalara bağlı olarak da görülebildiği kanıtlanmıștır. Șiddetli fiziki saldırılar sonrasında rabdomiyoliz ile ilișkili akut böbrek hasarı (rabdomiyoliz-akut böbrek hasarı) sık karșılașılan bir durum olmasa da literatürde karșılașılabilmektedir. Akut böbrek hasarının insan hayatını tehdit eden bir yönü olması dikkat edilmesini zorunlu kılmaktadır. Bu çalıșmada rabdomiyoliz-akut böbrek hasarı olarak tanı konulan iki olgu rapor edilmektedir. Birinci olgu 39 yașında erkek bir hastanın maruz kaldığı șiddetli fiziki saldırı sonrası bulantı-kusma ve akut böbrek hasarı, ikinci olgu ise 21 yașında erkek bir hastanın uzun mesafe koșusu ve sonrasında maruz kaldığı șiddetli fiziki saldırı sonrası yoğun dispeptik yakınma ve akut böbrek hasarı olup, bu hastalar acil servisimize bașvurdular. Her iki olguda da akılcı konservatif tedavi ile iyileșme sağlanmıș olup hemodiyalize ihtiyaç duyulmamıștır. Açıklanamayan șiddetli dispeptik yakınma ile acil polikliniğine bașvuran hastalarda hekimlerin rabdomiyoliz-akut böbrek hasarı olasılı̆ıın göz önünde bulundurması gerekmektedir. Erken tanı ve tedavi, rabdomiyoliz ile ortaya çıkabilecek akut böbrek yetmezliğini önleyebilir ve rabdomiyoliz hastalarında böbrek fonksiyon bozukluğunun potansiyel olumsuz etkilerini en aza indirebilir.

Anahtar Kelimeler: Rabdomiyoliz, Şiddetli fiziki saldırı, Akut Böbrek Hasarı, Bulantı, Kusma

\section{Abstract}

Two Cases Rhabdomyolysis Presented by Nausea and Vomiting

It has been proved that rhabdomyolysis, which can be occurred by many different causes, can also be observed due to traumas. Although severe acute kidney injury associated with rhabdomyolysis (rhabdomyolysis-acute kidney injury) after severe physical attacks is not common, it can be encountered in the literature. Acute kidney injury should be considered as a life-threating case. In this study, two cases diagnosed as rhabdomyolysis-acute kidney injury are reported. In the first case, 39-year-old male patient applied to our emergency department due to nausea-vomiting and acute kidney injury after exposed to a severe physical attack, and in the second case 21-year-old male patient applied to our emergency department due to severe dyspeptic complaints and acute kidney injury after exposed to a severe physical attack and long-distance run. In both cases, the recovery was provided with rational conservative treatment and hemodialysis was not required. Physicians should consider the possibility of rhabdomyolysis-acute kidney injury in patients who applied to the emergency department due to unexplained severe dyspeptic complaints. Early diagnosis and treatment may prevent acute renal failure associated with rhabdomyolysis and minimize the potential adverse effects of renal dysfunction in rhabdomyolysis patients.

Keywords: Rhabdomyolysis, Severe Physical Attack, Acute Kidney Injury, Nausea, Vomiting

\section{GİRİ̧̧}

Kas hücresinde kas enzimleri [kreatin fosfokinaz (CK), laktat dehidrogenaz (LHD)], aspartat aminotransferaz (AST), hem pigment miyoglobin, elektrolitler [(potasyum (K), fosfat $(\mathrm{P})$ ] ve pürinler bulunur. Rabdomiyoliz (RM) iskelet kas yıkımı ve demin söz edilen kas hücre içeriğinin dolaşım sistemine salınımı ile karakterizedir ( 1 , 2). RM etyolojisi travmatik ve non-travmatik nedenlere göre sinıflandırılır. Non-travmatik nedenler arasında yorucu egzersiz, toksinler, enfeksiyonlar, hipertermi, eğlence ilaçları, bazı ilaçların yan etkileri, metabolik anormallikler, elektrolit bozuklukları ve hipotiroidizm vb. sayılabilir $(3,4)$. RM genellikle belirgin olarak yüksek CK seviyesi, kas ağrısı, ekstremite güçsüzlüğü, şişlik ve miyoglobinüri ile kendini gösterir. RM spektrumu asemptomatik serum kas enzim yüksekliğinden hayatı tehdit eden uç enzim yüksekliğine, elektrolit dengesizliğine ve renal replasman tedavisi gerektiren akut böbrek hasarına (AKI) kadar ilerler (5). RM primer ve en tehlikeli komplikasyonu AKI'dir. RM'li hastaların \%13-50 arasında AKI gelişir (6).

Birinci vakamız şiddetli fiziksel travmaya bağlı, ikinci vakamız uzun mesafe koşusu ve şiddetli fiziksel travmaya bağlı RM-AKI komplikasyonu gelişti. Her iki vakamızı acile getirten yoğun dispeptik yakınmalarıydı. Literatürü kapsamlı bir şekilde analiz 
ettiğimizde şiddetli bulantı-kusma yakınmaları ile presentasyon gösteren sadece bir tane rabdomiyoliz vaka bildirisine ulaştık. Özgeçmişlerinde bu tabloyu yapabilecek başka bir sebep bulunamadı. İki ilginç ve aynı presentasyonu gösteren RM-AKI vakalarını bildiriyoruz.

\begin{tabular}{|c|c|c|c|c|c|}
\hline Veri & Üç Gün ${ }^{x}$ & Beş Gün ${ }^{x}$ & Altı Gün ${ }^{\mathrm{X}}$ & Sekiz Gün ${ }^{x}$ & Referans aralık \\
\hline Glukoz & & 86 & 93 & & $70-110 \mathrm{mg} / \mathrm{dL}$ \\
\hline Üre & 150 & 127 & 96 & 44 & $17-43 \mathrm{mg} / \mathrm{dL}$ \\
\hline Cre & 11,87 & 6,5 & 3,72 & 1,2 & $0.7-1,3 \mathrm{mg} / \mathrm{dL}$ \\
\hline Ürik asit & & 12,1 & 10,27 & 7,14 & $3,5-7,2 \mathrm{mg} / \mathrm{dL}$ \\
\hline Alb & & 34,9 & 33,3 & & $35-52 \mathrm{~g} / \mathrm{L}$ \\
\hline $\mathrm{Na}$ & & 136 & 141 & 142 & $136-146 \mathrm{mEql} / \mathrm{L}$ \\
\hline $\mathbf{K}$ & & 4,2 & 4,5 & 4,1 & $3,5-5,1 \mathrm{mEql} / \mathrm{L}$ \\
\hline CL & & 100 & 105 & 107 & 101-109 mEql/L \\
\hline $\mathrm{Ca}$ & & 8,4 & 9 & 9,4 & $8,8-10,6 \mathrm{mg} / \mathrm{dL}$ \\
\hline AST & 41 & 31 & 28 & 32 & $0-50 \mathrm{U} / \mathrm{L}$ \\
\hline ALT & 45 & 43 & 43 & & $0-50 \mathrm{U} / \mathrm{L}$ \\
\hline T. BİL & & 1,22 & 1,39 & & $0,3-1,2 \mathrm{mg} / \mathrm{dL}$ \\
\hline D.BİL & & 0,24 & 0,33 & & $0-0,2 \mathrm{mg} / \mathrm{dL}$ \\
\hline İ. BİL & & 0,98 & 1,06 & & $0-0,7 \mathrm{mg} / \mathrm{dL}$ \\
\hline LDH & & 356 & 320 & & $0-248 \mathrm{U} / \mathrm{L}$ \\
\hline CK & & 447 & 273 & 151 & $0-171 \mathrm{U} / \mathrm{L}$ \\
\hline $\mathbf{P}$ & & 4,7 & 4,3 & 3,5 & $2,5-4,5 \mathrm{mg} / \mathrm{dL}$ \\
\hline CRP & & 13,4 & 9,6 & & $0-5 \mathrm{mg} / \mathrm{L}$ \\
\hline MYG & & 1506,6 & & & $28-72 \mathrm{ng} / \mathrm{ml}$ \\
\hline WBC & 9,65 & & & & X109 / L \\
\hline HGB & 13,6 & & & & $12-18 \mathrm{~g} / \mathrm{dL}$ \\
\hline RBC & 4,65 & & & & $\mathrm{X} 1012$ / L \\
\hline PLT & 188 & & & & X109 / L \\
\hline $\mathbf{P h}$ & & 7,36 & 7,39 & 7,38 & $7,35-7,45$ \\
\hline PCO2 & & 44,2 & 44,5 & 48,1 & $35-45 \mathrm{mmHg}$ \\
\hline HCO3 & & 22,7 & 25,4 & 25,6 & $22-30 \mathrm{mmol} / \mathrm{L}$ \\
\hline \multicolumn{6}{|c|}{$\begin{array}{l}\text { x: Fiziki şiddet sonrası zamanı belirtir } \\
\text { Kısaltmalar; Cre: Kreatinin, Alb: Albumin, Na: Sodyum, K: Potasyum, CL: Klorid, Ca: Kalsiyum, } \\
\text { AST: Aspartat aminotransferaz, ALT: Alanin aminotransferaz, T.BILL: Total bilirubin, D.BİL: } \\
\text { Direkt bilirubin, I.BİL: İndirekt bilirubin, LDH: Laktat dehidrogenaz, CK: Kreatin fosfokinaz, P: } \\
\text { Fosfor, CRP: C reaktive protein, MYG: Miyoglobin, WBC: White blood cell, HGB: Hemoglobin, } \\
\text { RBC: Red blood cell, HCT:hematocrit, PLT: Platelet, pCO2: karbondioksit parsiyel basincı, } \\
\text { HCO3: Bikarbonat }\end{array}$} \\
\hline
\end{tabular}

\section{OLGU}

Vaka 1: 39 yaşında erkek idi. Arazi paylaşımı nedeniyle akrabaları ile anlaşmazlığı yıllardır bulunuyormuş. 3 gün önce hastamızla akrabaları arasında tartışma yaşanmış. 4-5 kişi tarafından şiddetli dövülmüş. Sopa, yumruk, tekme darbeleri almış. Sonrasında bulantı ve kusma başlamış. Yoğun dispeptik yakınmaları oral alımı bozuyormuş. İdrarında koyulaşma eşlik etmiş. Acil servisimize getirildi. Muayenede; nabız sayısı: 105 / dk, kan basıncı 90/50 mm $\mathrm{Hg}$, ateş $37,5^{\circ} \mathrm{C}$ tespit edildi. Laboratuvar incelemelerinde; üre: $150 \mathrm{mg} / \mathrm{dL}$, kreatinin (Cre): 11,87 mg/dL, ürik asit: 12,1 mg/dL, sodyum (Na): $136 \mathrm{mEq} / \mathrm{L}, \mathrm{K}: 4,2 \mathrm{mEq} / \mathrm{L}$, AST:
$31 \mathrm{U} / \mathrm{L}$, alanin aminotransferaz (ALT): $43 \mathrm{U} / \mathrm{L}$, total bilirubin (T.BİL): 1,22 mg/dL, direkt bilirubin (D.BİL): 0,24 mg/ $\mathrm{dL}$, indirekt bilirubin (İ.BİL): 0,98 mg/dL, LDH: $356 \mathrm{U} / \mathrm{L}$, CK: 447 U/L, white blood cell (WBC): 7,48x109/L, hemoglobin (HGB): 11,7 g/dL, platelet (PLT): 185x10 $/ \mathrm{L}$, miyoglobin (MYG): 1506,6 ng/mL, C-reaktive protein (CRP): 13,4 mg/L, ph: 7,36, pCO2: 44,2 mmHg, HCO3: 22,7 mmol/L sonuçları bulundu (Tablo 1). İdrar Na düzeyi ve idrar $\mathrm{Na}$ fraksiyonu yüksekti (sırasıyla $46 \mathrm{mEq} / \mathrm{L}, \% 2$ ).

Vaka 2: 21 yaşında erkek idi. Çocukluk yıllarında babası gözü önünde silahla öldürülmüş. Kendisine tabanca almış. Babasının intikamı alma hayali varmış. Şehirden uzak bir yerde silah atışı yapıyormuş. Emniyet mensupları ihbar üzerine hastamızın atıș yaptığı alana gelmișler. Hastamızın bir terör faaliyetine girişebileceğini zannedip yakalamaya çalışmışlar. Hasta o alandan kaçmaya başlamış. Elindeki silahın ruhsatı yokmuş. Hastamızın o esnada iki korkusu varmıș. Birincisi silahının elinden alınması, ikincisi cezaevine girmesi. Hasta var gücüyle kaçmış. Anlattığına göre, yaklaşık olarak 7 kilometre gibi uzun bir mesafeyi ağır bir eforla koşmuş. Emniyet mensupları onu yakalamışlar. 4-5 polis tarafından tekme-tokat-jop-sopa ile yarım saat boyunca fiziksel şiddet uygulanmış. Elinden silahını almışlar. Karakolda ifadesi alındıktan sonra serbest bırakılmış. Yaşadığ fiziki saldırı akabinde yoğun bulantı ve kusma yakınmaları nedeniyle oral alımı azalmıș. İdrarında koyulaşma eşlik etmiş. Acil servisimize getirildi. Muayenede; nabız sayısı: 98 / dk, kan basıncı 100/50 mm Hg, ateş $37,6{ }^{\circ} \mathrm{C}$ tespit edildi. Laboratuvar incelemelerinde; üre: $73 \mathrm{mg} / \mathrm{dL}$, Cre: 5,78mg/ dL, ürik asit: 14,37 mg/dL, Na: $140 \mathrm{mEq} / \mathrm{L}, \mathrm{K}: 4,3 \mathrm{mEq} / \mathrm{L}$, AST: 32 U/L, ALT: 61 U/L, T.BİL: 1,03 mg/dL, D.BİL: 0,3 mg/ dL, İ.BİL: 0,73 mg/dL, LDH: 250 U/L , CK: 919 U/L, WBC: 10,08x10\%/L, HGB: $14 \mathrm{~g} / \mathrm{dL}, \mathrm{PLT}: 175 \times 10^{9} / \mathrm{L}, \mathrm{MYG}: 1760 \mathrm{ng} /$ mL, CRP: 55,3 mg/L, ph: 7,37, pCO2: 42,8 mmHg, HCO3: $22,9 \mathrm{mmol} / \mathrm{L}$ sonuçları bulundu (Tablo 2 ). İdrar Na düzeyi ve idrar Na fraksiyonu yüksekti (sirasıyla $40 \mathrm{mEq} / \mathrm{L}, \% 2$ ).

Hastalarımızın özgeçmişlerinde böbrek hastalığı, kronik bir hastalık ve kontrolsüz kan şekeri, enfeksiyon ve viral ekzantemi, havale, ağır egzerzis, sigara, alkol, ilaç (statin, bitkisel ilaç gibi) ve toksin kullanımı gibi durumlar dışlandı. Boyunlarında guatr belirtisi yoktu. Her iki vakamızın sistemik olarak vücudun bazı bölgelerinde (kol-sırt-göğüs) ekimotik alanlar bulundu. Fizik muayenelerinde abdomen ve extremite kaslarında hassasiyet vardı. Kardiyak enzim, hepatit, tiroid ve lipid profilleri normaldı. Tüm abdomen ultrasonografilerinde bir patoloji bulunmadi. Gasroduodenoskopileri normal bulundu. Her iki vakaya paranteral hidrasyon, bikarbonat, parasetamol, antiasid verildi. İdrarları koyu kırmızı renkte ve idrar analizinde dipstick testi ile kan reaksiyonu görüldü, ancak mikroskobik incelemede eritrosit yoktu. Dispeptik yakınmaları ve üremik tabloları konservatif tedaviye cevap verince hemodiyaliz ihtiyacı olmadı. Böbrek fonksiyonları yaklaşık olarak 7-10 gün içinde normale geldi ve idrar renkleri açıldı. Şifa ile taburcu edildiler. 


\begin{tabular}{|c|c|c|c|c|c|c|}
\hline Veri & Dört Güny & Beş Güny & Altı Güny & Sekiz Güny & On Güny & Referans aralık \\
\hline Glukoz & & 89 & 103 & 103 & 98 & $70-110 \mathrm{mg} / \mathrm{dL}$ \\
\hline Üre & 73 & 76 & 73 & 88 & 49 & $17-43 \mathrm{mg} / \mathrm{dL}$ \\
\hline Cre & 5,78 & 5,77 & 5,13 & 3,94 & 1,3 & $0,7-1,3 \mathrm{mg} / \mathrm{dL}$ \\
\hline Ürik asit & 14,37 & 13,91 & 12,58 & 11,61 & 8,17 & $3,5-7,2 \mathrm{mg} / \mathrm{dL}$ \\
\hline ALB & 41,2 & 37,5 & 39,5 & 37,6 & 36,8 & $35-52 \mathrm{~g} / \mathrm{dL}$ \\
\hline $\mathrm{Na}$ & 140 & 140 & 144 & 142 & 143 & $136-146 \mathrm{mEq1} / \mathrm{L}$ \\
\hline $\mathbf{K}$ & 4,3 & 4 & 4,3 & 4 & 3,8 & $3,5-5,1 \mathrm{mEq} / / \mathrm{L}$ \\
\hline CL & 101 & 104 & 102 & 99 & 100 & $101-109 \mathrm{mEq} 1 / \mathrm{L}$ \\
\hline $\mathrm{Ca}$ & 9,5 & 8,7 & 9,1 & 8,9 & 9,4 & $8,8-10,6 \mathrm{mg} / \mathrm{dL}$ \\
\hline AST & 32 & 23 & 20 & & 20 & $0-50 \mathrm{U} / \mathrm{L}$ \\
\hline ALT & 61 & 19 & 18 & & 17 & $0-50 \mathrm{U} / \mathrm{L}$ \\
\hline T. BIL & 1,03 & 0,97 & 0,92 & & 0,53 & $0,3-1,2 \mathrm{mg} / \mathrm{dL}$ \\
\hline D.BIL & 0,3 & 0,21 & 0,26 & & 0,17 & $0-0,2 \mathrm{mg} / \mathrm{dL}$ \\
\hline İ. BíL & 0,73 & 0,76 & 0,66 & & 0,36 & $0-0,7 \mathrm{mg} / \mathrm{dL}$ \\
\hline LDH & 250 & & 239 & & 189 & $0-248 \mathrm{U} / \mathrm{L}$ \\
\hline CK & 919 & 581 & 636 & & 146 & 0-171 U / L \\
\hline $\mathbf{P}$ & 4,4 & 5,2 & 4,1 & 4,3 & 4,7 & $2,5-4,5 \mathrm{mg} / \mathrm{dL}$ \\
\hline CRP & 55,3 & 48 & 36 & & 16,6 & $0-5 \mathrm{mg} / \mathrm{L}$ \\
\hline MYG & 1760 & & & & & $28-72 \mathrm{ng} / \mathrm{ml}$ \\
\hline WBC & 8.21 & & & & & $\mathrm{X} 10^{9} / \mathrm{L}$ \\
\hline HGB & 14,9 & & & & & $12-18 \mathrm{~g} / \mathrm{dL}$ \\
\hline RBC & 5.09 & & & & & $\mathrm{X} 10^{12} / \mathrm{L}$ \\
\hline PLT & 228 & & & & & $\mathrm{X} 10^{9} / \mathrm{L}$ \\
\hline $\mathbf{P h}$ & 7,37 & 7,39 & 7,35 & 7,4 & & $7,35-7,45$ \\
\hline PCO2 & 42,8 & 39,6 & 45,5 & 48,8 & & $35-45 \mathrm{mmHg}$ \\
\hline HCO3 & 22,9 & 23,3 & 23 & 28,5 & & $22-30 \mathrm{mmol} / \mathrm{L}$ \\
\hline \multicolumn{7}{|c|}{ y: Fiziki şiddet sonrası zamanı belirtir } \\
\hline \multicolumn{7}{|c|}{$\begin{array}{l}\text { Kisaltmalar; Cre: Kreatinin, Alb: Albumin, Na: Sodyum, K: Potasyum, CL: Klorid, Ca: Kalsiyum, } \\
\text { AST: Aspartat aminotransferaz, ALT: Alanin aminotransferaz, T.BIL: Total bilirubin, D.BIL: } \\
\text { Direkt bilirubin, I.BIL: Indirekt bilirubin, LDH: Laktat dehidrogenaz, CK: Kreatin fosfokinaz, P: } \\
\text { Fosfor, CRP: C reaktive protein, MYG: Miyoglobin, WBC: White blood cell, HGB: Hemoglobin, } \\
\text { RBC: Red blood cell, HCT:hematocrit, PLT: Platelet, pCO2: karbondioksit parsiyel basıncl, } \\
\text { HCO3: Bikarbonat. }\end{array}$} \\
\hline
\end{tabular}

\section{Etik Beyan}

Bu çalışmada tanımlanan olgulardan gerekli izin alınarak "Aydınlatılmış onam formu" düzenlenmiş, Helsinki Bildirgesi kriterleri göz önünde bulundurulmuştur.

\section{TARTIŞMA}

Rabdomiyoliz çok çeşitli nedenlerle ilişkilidir. RM'in patogenezi, doğrudan sarkolemik yaralanmayla (travma gibi) veya miyositler içindeki ATP'nin tükenmesiyle ilintilidir ve hücre dıșından hücre içine Ca iyonlarının düzensiz bir şekilde sızmasına yol açar (7). Sarkoplasmik Ca, sarkolemmadaki $\mathrm{Na}^{+1} / \mathrm{K}^{+1}$ ATPaz ve $\mathrm{Ca}^{+2}$ ATPaz gibi enerji bağımlı iyon pompaları tarafından sıkı bir şekilde düzenlenir. Bu pompalar istirahat halindeki kasta Ca seviyelerini düșük tutar, ancak aktin-miyozin bağlanması ve kas kasılması gerekli olduğunda ise Ca seviyelerinin artışına izin verir. Altta yatan mekanizmadan bağımsız olarak, kas yaralanması sarkoplazmik Ca arttırır ve persistan kontraksiyon artışına neden olur. Son olarak, hücre proteazı aktive olmasından sonra kas lifi nekrozu olur. Akabinde hücre dışına ve sistemik dolaşıma K, P, MYG, CK ve ürik asit salınır (5).

RM-AKI çeşitli nedenlerle ortaya çıkmaktadır. Mahkumlarda ve göz altına alınan şüphelilerde yapılan işkencelerde AKI bildirilmiş (8). Bir vaka seri çalışmasında; birinci vaka bildirisi hipotiroidi sonrasında, ikinci vaka bildirisi fluriprofen / tiyokolşikosid ve amoksisilin / klavulanik asit kombinasyonu kullanımı sonrasında RM-AKI bulundu (9). Literatürde vakamıza benzer sadece bir vaka bildirisine tanık olduk. Yumuşak doku hasarı olmayan spinal kord hasarıyla ilişkili RM olgusunda, bulantı ve kusma tablosuyla presente olmuş (10). Bu vakada böbrek yetmezliği bulunmuyordu. Ama bizim çalışmamızda kas hasarı vardı. Bununla birlikte, söz konusu makalede RM ilişkili fiziki saldırı yoktur. Her iki vakamızda öncesine dayanan bir gastrointestinal rahatsızlık yoktur. Bu vakalarımızda, başvuru semptomları daha önce bildirilen vakadan farklıdır (5], çünkü başlıca şikayetler bulantı ve kusmadır. İlginç olanı iki hastamız aynı hafta içinde art arda bize başvurdu.

Birinci olguda, CK, LDH seviyesi normal sınırın biraz üstündeyken, MYG çok yüksek olarak ölçüldü. Biyokimyasal analizde üremi, sınırda hiperbilirubinemi, ürik asid yüksekliği eşlik ediyordu.

İkinci olguda, CK seviyesi normal sınırdan çok daha yüksek olarak ölçüldü. LDH normal üst sınırın biraz daha üstündeydi. Biyokimyasal analizde üremi, ürik asid yüksekliği eşlik ediyordu. Serumda miyoglobin oldukça yüksekti. Fizik muayenede ateşi yoktu. CRP'de sınırda bir yükseklik vardı. Enfeksiyona yol açabilecek bir odak bulunamadı. İdrar ve kan kültürlerinde üreme olmadı.

Her iki vakamızda İdrarın dipstick testi ile pozitif kan reaksiyonu göstermesi, ancak mikroskobik incelemede eritrosit bulunmaması da RM-AKI düşünüldü. RM'in etyolojik sebepleri açısından hastalardan ayrıntılı olarak anemnez alındı ve ek tetkikler yapıldı. Her iki vakada sırtta-göğüste-ekstremitede yumuşak dokuda travma izi ve ekimozlar bulunuyordu. Ek olarak her iki vakada dispeptik yakınmalar koyu renkli idrardan önce ortaya çıtı. Fizik saldırı sonrasında; birinci olgu 3.günde, ikinci olgu 4.günde bize başvurdu. 1.olguda RM'un şiddetli fiziki saldırı dışında, 2.olguda şiddetli fiziki saldırı ve uzun mesafe koşusu dışında tetikleyici bir başka nedeni yoktu. Dolayısıyla her iki olgunun RM ve AKI tabloları, demin sözü ettiğim temel etmenlere bağlandı.

Her iki olguya mai, bikarbonat verildi. İstirahat ettirildi. RM'li hastaların tedavisinde ileri yaşam desteği var. Bu da 
böbrek fonksiyonlarını korumak için gerekli önlemleri içerir. Retrospektif analiz, salin ile erken agresif sıvı replasmanının AKI oluşumunu en aza indirmede yararlı olduğunu göstermiştir. Salin tedavisi sonrası, alkali ajanlar (bikarbonat) ve zorla diürez (mannitol veya furosemid) 6 saat içinde başlanması AKI riskini en aza indirdiği rapor edilmiştir. Amaç intratübüler hem pigment birikimini en aza indirgemek ve serbest radikal temizleyici olarak hareket etmek, böylece hücre hasarını en aza indirmektir (11-16).

Sonuç olarak, rabdomiyoliz bulantı-kusma ile presente olabilir. Yoğun dispeptik yakınmalar kas ve eklem ağrısının önüne geçebilir. Oral alım bozukluğu sonrasında hipovolemi ve şiddetli fiziki saldırı ile ortaya çıkan kas yıkımı sonrasında AKI kaçınılmazdır. Zamanında AKI'ye müdahale edilmezse mortal olabilir. Dikkatli ve uygun sıvı replasmanı ile hemodiyalize gereksinim olmadan mortalitesi yüksek tablodan hasta kurtulabilir.

\section{KAYNAKLAR}

1. Sauret JM, Marinides G, Wang GK. Rhabdomyolysis. Am Fam Physician. 2002; 65: 907-912.

2. Lane R, Phillips M. Rhabdomyolysis. BMJ. 2003; 327: 115-116. https://doi.org/10.1136/bmj.327.7407.115

3. Lima RS, da Silva Junior GB, Liborio AB et al. Acute kidney injury due to rhabdomyolysis. Saudi J Kidney Dis Transpl 2008; 19: 721-9.

4. Melli G, Chaudhry V, Cornblath DR. Rhabdomyolysis: an evaluation of 475 hospitalized patients. Medicine (Baltimore) 2005; 84: 37785. https://doi.org/10.1097/01.md.0000188565.48918.41

5. Khan FY. Rhabdomyolysis: a review of the literature. Neth J Med. 2009; 67: 272-283.

6. Bosch X, Poch E, Grau JM. Rhabdomyolysis and acute kidney injury. N Engl J Med. 2009; 361: 62-72. https://doi.org/10.1056/
NEJMra0801327

7. Giannoglou GD, Chatzizisis YS, Misirli G. The syndrome of rhabdomyolysis: pathophysiology and diagnosis. Eur J Intern Med. 2007; 18: 90-100. https://doi.org/10.1016/j.ejim.2006.09.020

8. Malik GH, Sirwal IA, Reshi AR, et al. Acute renal failure following physical torture. Nephron. 1993; 63(4): 434-7. https://doi. org/10.1159/000187248

9. Kemeç Z, Gürel A, Demir M, et al. Hypothyroıdısm and DrugRelated Rhabdomyolısıs and Acute Kıdney Injury. Sch J Med Case Rep. 2019; 7(1): 55-58.

10. Seoul, Korea. Rhabdomyolysis in acute spinal cord Injury presenting with nausea and vomiting as chief complaints: a Case Report. Annals of Rehabilitation Medicine 2014; 38(4): 559-562. https://doi.org/10.5535/arm.2014.38.4.559

11. Holt SG, Moore KP. Pathogenesis and treatment of renal dysfunction in rhabdomyolysis. Intensive Care Med. 2001; 27: 803-811. https:// doi.org/10.1007/s001340100878

12. Kreisman SH, Hennessey JV. Consistent reversible elevations of serum creatinine levels in severe hypothyroidism. Arch Intern Med 1999; 2013: 79. https://doi.org/10.1001/archinte.159.1.79

13. Huerta-Alardín AL, Varon J, Marik PE. Bench-to-bedside review: rhabdomyolysis an overview for clinicians. Crit Care 2005; 2013: 2

14. Knottenbelt J. Traumatic rhabdomyolysis from severe beating experience of volume diuresis in 200 patients. J Trauma 1994; 2013: 214-19 https://doi.org/10.1097/00005373-199408000-00011

15. Odeh M.The role of reperfusion-induced injury in the pathogenesis of the crush syndrome. N Engl J Med 1991; 2013: 1417-22 https:// doi.org/10.1056/NEJM199105163242007

16. Homsi E, Barreiro M, Orlando J, et al. Prophylaxis of acute renal failure in patients with rhabdomyolysis. Ren Fail 1997; 2013: 283-8 https://doi.org/10.3109/08860229709026290 